\title{
Beyond CO2: A multi-criteria analysis of air pollution in Europe
}

\author{
Nicola Caravaggio, Department of Economics, Roma Tre University, Italy \\ Serenella Caravella, Department of Economics, Roma Tre University, Italy \\ Alessio Ishizaka, Portsmouth Business School, University of Portsmouth, United Kingdom \\ Giuliano Resce, Italian National Research Council, Italy
}

\begin{abstract}
Environmental-economic perspectives are recently taking growing momentum in the analysis of country-level performances, but few studies take into account the multi-dimensional nature of the phenomenon. The leading measure of pollution still remains only $\mathrm{CO} 2$ emission or, at best, $\mathrm{CO} 2$ equivalent emission. The few works taking a multi-criteria perspective are mainly related to specific case studies, urban areas, or the localization of renewable power plants. In this paper, we propose a multi-criteria analysis for a macro-perspective assessment of 10 different pollutants in 30 European countries over the period 2008-2015. Methodologically, we propose a new hybrid tool allowing us to merge the consolidated procedure usually employed for environmental evaluation: PROMETHEE, with a more flexible weighing process inspired by Data Envelopment Analysis. The unprecedented use of this tool for developing a macro perspective allows the clustering of European countries according their relative performances without any exogenous assumption about the weights given to the specific pollutants. In addition, the empirical evidence emerging from the analysis provides a comprehensive picture of patterns followed by European economies, which highlights the relative strengths and flaws at country-level for the considered pollutants.
\end{abstract}

Keywords: Environment; Sustainability; Pollutants; PROMETHEE; Data Envelopment Analysis

\section{Introduction}

The analysis of country-level performances is increasingly focusing in the dynamics and interaction between environment and economic. Given the largely documented health endpoints associated with pollutants (Nemery et al., 2001), such a growing interest reflects the awareness about the key role played by environmental issues in ensuring people's well-being. This is proven by the inclusion of environmental objectives among the agendas of the main international organizations, such as the Sustainable Development Goals (SDGs) set by United Nations and the Better Life index indicators proposed by the Organisation for Economic Co-operation and Development (OECD, 2016; Costanza et al., 2016). 
In particular, such an "environment alertness" has begun to take increasing momentum in the last decades, when the amount of greenhouse gas emissions (GHG) in the atmosphere has raised up to alarming levels. As GHGs have been acknowledged as being the primary responsible for global warming (IPCC, 2015), many policy actions have been aimed at counteracting its anthropogenic causes. For instance, the ratification of the international treaty of 1997, known as Kyoto protocol, by countries of the European Union (EU), lead the way to a cap-and-trade system called European Emission Trading Scheme (ETS). This scheme committed European State Parties of the United Nations Framework Convention on Climate Change (UNFCCC) to reduce GHG emissions by 9\% (compared to 1990 levels) over the period 2005-2012. A goal that has been achieved by the EU, but mostly because of the economic recession and the enlargement of the union to Eastern countries (Borghesi, 2011). More recently, the achievement of the "zero emissions" goal has been declared by 196 countries in 2015 during the 21st Conference of the Parties of the UNFCCC (2018). By this Paris Agreement, countries have been left substantially free as to the way they choose to achieve the target of zero GHG net emissions by the end of this century-although it would better to accomplish the goal by 2070 .

Since carbon dioxide $\left(\mathrm{CO}_{2}\right)$ is the most common pollutant emitted by human activities, policy targets are usually expressed in $\mathrm{CO}_{2}$ equivalent $\left(\mathrm{CO}_{2} \mathrm{e}\right)$, that properly refer to the amount of carbon dioxide that would give the same warming effect as the effect of the greenhouse gas or greenhouse gases being emitted. However, using $\mathrm{CO}_{2} \mathrm{e}$ as standard unit might neglect two main issues. Firstly, the $\mathrm{CO}_{2} \mathrm{e}$ standard unit not allows for considering the whole spectrum of harmful substances, as only certain pollutants may be indicated in $\mathrm{CO}_{2} \mathrm{e}(\mathrm{CH} 4, \mathrm{CO} 2, \mathrm{HFCS}, \mathrm{NF} 3$, N20, PFCS, and SF6). Secondly, measuring air pollution in $\mathrm{CO}_{2}$ equivalent means that global warming potentials should have common weights for all countries. Nevertheless, this assumption denies two main fact. On the one hand, country-level performances expressed in terms of quantity of pollution effectively produced reflect a plethora of factors that are strictly linked to country-specific aspects, such as forest density, economic structure and specialization, level of technological progress, and state of development. On the other hand, the negative impact of a gas is not only on global warming as it inevitably embraces health issues, with effects that are differentiated across pollutants. All these aspects could vary among countries and pollutants as well, thus there is no reason to assume that they can be represented by some sort of common weights.

So that, coping with the above issues requires to adopt a multi-criteria decision method. To give a contribution in this direction, here we made use of a multidimensional approach, which appears to be particularly suitable for the evaluation of countries environmental performances when the heterogeneous sources of air pollution, as well as their differentiated impacts on human health, are accounted for. In detail, we propose a Preference Ranking Organization METHod for the Enrichment of Evaluations with Optimal Weights (PROMETHEE-OW) method. At the best of the authors' knowledge, this is to date the first empirical attempt to estimate countries' environmental performances on the basis of the multidimensionality nature of pollution taking into account differentiated countryspecific weights. The analysis concentrates on the EU area with the inclusion of Norway and Switzerland performing a cross-country analysis over the period 2008-2015. 
The paper is organized as follows. Section 2 presents the literature review, while section 3 describes the new methodology. Section 4 presents the data, section 5 and 6 report results and discussion while section 7 contains the conclusions.

\section{Literature Review}

In this paper, we propose a multi-criteria analysis for a macro-perspective assessment for 30 European countries over the period 2008-2015. The use of the multidimensional approach for performing evaluation studies is, to date, very rare in the literature investigating economic and environmental relations. Scholars are mainly focused on a unique value for an environmental degradation $\left(\mathrm{CO}_{2}\right.$ equivalents) and only few studies make use of a multicriteria approach.

The issue of how to synthesize multidimensional information into one metric has recently paved the way to the development of composite indicators (see Nardo et al., 2008; Costanza et al., 2016). As mentioned in Greco et al. (2018), adopting a multi-dimensional approach rises three main issues, i.e. (i) which indicators should be considered; (ii) which aggregation rule should be chosen (ii) how to weight the indicators to collapse multidimensionality into one single metric (Greco et al. 2018). In what follows we describe the way these three issues are faced in previous studies and how this paper contributes to the literature.

\subsection{Choice of indicators}

The issue of choice of indicators is strictly related to the comprehensive definition of "air pollution". It is commonly associated with indoor and outdoor environmental contamination by some gases and solids that substantially modify the natural characteristic of the atmosphere. Among them, "air" pollutants are supposed to be the major environmental health issue (Brunekreef and Holgate, 2002) as they have been found to cause mortality and morbidity in hundreds of thousands of people in Europe and USA during the twentieth century (Nemery et al., 2001). For a comprehensive analysis of air pollution, the $\mathrm{CO}_{2}$ equivalent could be not appropriate since it does not consider the whole spectrum of harmful substances. In general, the impacts of air pollution on human health are disentangled in short and long-term risks. The former provokes cardiovascular or respiratory problems, while the latter lead to lung cancer, heart attacks, death from stroke or coronary disease, and more generally to a reduction of life expectancy (Kampa and Castanas, 2008). The most common health-harmful pollutants belonging to the "air pollution" category have been identified as follows: particulate matter with a diameter of less than 5 and $10 \mu \mathrm{m}$ $\left(\mathrm{PM}_{2.5}\right.$ and $\left.\mathrm{PM}_{10}\right)$, carbon monoxide $(\mathrm{CO})$, ozone $\left(\mathrm{O}_{3}\right)$, black carbon $(\mathrm{BC})$, sulphur dioxide $\left(\mathrm{SO}_{2}\right)$, and nitrogen oxides $\left(\mathrm{NO}_{\mathrm{x}}\right)(\mathrm{WHO}, 2018)$. Each year in European cities where the levels of these pollutants exceed those levels defined by the World Health Organization (WHO), 436,000 premature deaths are recorded. In general, sanitary problems due to air pollution are extremely serious in areas characterized by low urban forest density (Irga et al., 2015) and a semi-arid climate. 
All of these issues make clear that air pollution evaluations require multidimensionality which in turn brings the problems of aggregation rule and weights (Greco et al. 2018).

\subsection{Aggregation rule}

On the aggregation rule, the main categorization in the literature is between compensatory and non-compensatory approaches (Munda 2005). Compensatory requires the assumption that a unit can compensate for the loss in one dimension with a gain in another (Nardo et al. 2008; Munda and Nardo, 2009). Simple or weighted average/sum of different indicators (as in the case of $\mathrm{CO}_{2}$ equivalent) as well as the standard Data Envelopment Analysis (DEA - Charnes et al., 1978) applications are a fully compensatory approaches. Of course, granular and important information can be lost by such assumption.

One of the most important non-compensatory aggregation techniques is PROMETHEE (Brans and Vincke, 1985; Brans and De Smet, 2016). The PROMETHEE method belongs to the family of outranking methods (Ishizaka, Nemery, 2013), which is based on pairwise comparisons, and permits to represent indifference, strict preference, and incomparability between options. For its desirable characteristics, PROMETHEE has been largely used to evaluate the air pollution in different urban areas, for assessing air quality in residential houses (Ayoko et al., 2004; Nikolić, et al., 2010; Coban et al., 2018), and recently for a macro evaluation in Europe (Antanasijević et al., 2017). A crucial and open issue in these studies is the assignment of weights.

\subsection{Weights}

Regarding the weights, Nardo et al. (2008) list several procedures in the construction of a composite index, with equal weighting being the most frequent solution (Floridi et al. 2011; Paruolo et al., 2013; Antanasijević et al., 2017). This method has been strongly criticized (Decancq and Lugo, 2013), mainly because it misses differentiating among important and non-important characteristics and the "double counting" problem may arise. Some work has preconized assigning weights proportional to the harmfulness or quality of the emission (Nikolić et al., 2010; Crnković et al., 2016; Deljanin et al., 2016), but it is not clear how harmfulness can be measured. Expert opinions can be used, but they are likely to be biased towards their subjective perception (Greco et al., 2018).

To avoid these shortcomings, in previous composite indices, the data-driven methods, in particular DEA without input (Benefit of Doubt - BoD), have been extensively employed as technique of aggregation (Decancq and Lugo, 2013; Patrizii et al., 2017, Greco et al., 2018). The basic assumption of DEA evaluations is that the status-quo is a choice of the decision maker (Cherchye et al., 2007). Based on this premise, DEA compiles multi-dimensional metrics into one index using the combination of weights that is the most convenient for the evaluated alternative. 


\subsection{Proposal}

In order to embody the most compelling solutions to the aggregation and weighting techniques, we propose a specific tool allowing joining the consolidated procedure usually employed for environmental evaluation: PROMETHEE (Brans and Vincke, 1985), with a more flexible weighing process inspired by DEA. In the standard PROMETHEE, the decision makers explicitly select the weights attached to the different criteria where the weights represent the relative importance of the criteria. An important feature of the standard PROMETHEE weights is that once selected, they remain the same for all the alternatives. However, there are some cases in which different alternatives have different objective functions, and there is no reason to assume that they can be represented by some sort of common weights. In the efficiency literature, DEA models do not require the assumption of a common technology (Patrizii and Resce, 2015). Following the DEA weighting process, our approach does not employ a common set of weights for all alternatives. Instead, for each alternative, a different set of weights is calculated with a linear optimization procedure. The aim of this optimization is to select weights in order to highlight the particular strength of the evaluated alternative. Constraints are added in order to ensure that none of scores obtained by candidates is higher than the maximum score obtained by a standard PROMETHEE evaluation. Moreover, as the method is a further development of PROMETHEE, it inherits all its advantages: it avoids the "compensation effects" (which means higher performance in a criterion can compensate for the lower performance in other criteria), it can incorporate thresholds, which means that above or below them the score does not contribute anymore to their overall performance. This feature is important because it avoids over-emphasizing criteria, which can be seen in DEA (Tofallis, 2008). Methodologically, our proposal differs from the classical PROMETHEE in two ways: the autogenous selection of weights rather than a subjective choice by a decision maker, and the fact that different weights characterize different alternatives. On the choice of indicators this paper contributes to the literature considering 10 air pollutants that are particularly harmful for human health and environmental balance when highly concentrated in the atmosphere: Methane $\left(\mathrm{CH}_{4}\right)$; Carbon monoxide $(\mathrm{CO})$; Carbon dioxide $\left(\mathrm{CO}_{2}\right)$; Ammonia $\left(\mathrm{NH}_{3}\right)$; Non-methane volatile organic compounds (NMVOC); Nitrous oxide $\left(\mathrm{N}_{2} \mathrm{O}\right)$; Nitrogen oxides

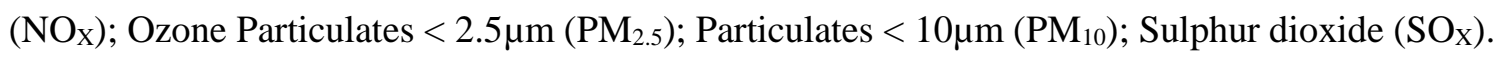

Our work differs from the Environmental Performance Index (EPI) developed by the Yale Center for Environmental Law \& Policy (Wendling et al., 2018). This composite index is made of different punctual weights associated to a large group of indicators divided into two broad categories (environmental health and ecosystem vitality) which does not refer only to air pollution, such as our case. Moreover, despite the considered pollutant of our analysis could be retrieved within EPI's sub-indicators, not all of them are directly included. Eventually, the EPI is not reported annually and is not fully comparable among different editions due to changes in weights whilst our study analyses a continuous time-span. 


\section{Methodology}

We propose a new technique based on the combination of PROMETHEE (Brans and Vincke, 1985; Brans et al., 1986) and DEA (Charnes et al., 1978). The standard PROMETHEE methods require from decision makers two sources of information: information between the criteria (weights) and information within each criterion (preference functions). The main difference with standard PROMETHEE is that in this model weights are calculated by means of an optimization process inspired by DEA.

Formally, we have $n$ alternatives in the set $A=\left\{a_{1}, \ldots, a_{n}\right\}$ which are evaluated on $m$ criteria in the set $F=\left\{f_{1}, \ldots, f_{m}\right\} . f_{k}\left(a_{i}\right)$ denotes the evaluation of the alternative $a_{i}$ on the criterion $f_{k}$. For each ordered pair of alternatives $\left(a_{i}, a_{j}\right)$, and for each criterion $\left(f_{k}\right)$, the decision maker expresses their preference by means of the unicriterion preference function $P_{k}\left(a_{i}, a_{j}\right)$. The unicriterion preference function $P_{k}\left(a_{i}, a_{j}\right)$ is a function of the difference between the alternative $a_{i}$ and the alternative $a_{j}$ on the criterion $k$, i.e. $f_{k}\left(a_{i}\right)-f_{k}\left(a_{j}\right)$. It is expressed in a number between 0 and 1 that indicates the extent to which the alternative $a_{i}$ is preferred or not to the alternative $a_{j}$ on the criterion $f_{k}$. Several typical shapes of preference function are proposed (Brans and Vincke, 1985): the linear, the level, and the Gaussian preference function (see Supplementary).

After the preference function selection, for each criterion $(k)$ and for each alternative $(i)$ we estimate the PROMETHEE unicriterion net flows:

$$
\phi_{k}\left(a_{i}\right)=\frac{1}{n-1} \sum_{j=1}^{n}\left[P_{k}\left(a_{i}, a_{j}\right)-P_{k}\left(a_{j}, a_{i}\right)\right], k=1, \ldots, m
$$

Equation 1 shows a measure of the number of times the $i$-th alternative is preferred over the other alternatives of the set, minus the number of times the $i$-th alternative is being preferred by other alternatives, on the $k$-th criterion.

In the basic PROMETHEE models, the decision makers explicitly select the weights attached to the different criteria where the weights represent the relative importance of the criteria (Ishizaka and Nemery, 2013). The main innovation in this study is to estimate the weights by means of a DEA optimization on the unicriterion net flows (Equation 2). More specifically, for each alternative we estimate the global score $\left(\phi\left(a_{i}\right)\right)$ by using the following linear program:

$$
\begin{gathered}
\phi\left(a_{i}\right)=\max _{w_{k}} \sum_{k=1}^{m} \phi_{k}\left(a_{i}\right) w_{k} \\
\sum_{k=1}^{m} w_{k}=1 \\
w_{k} \geq 0, k=1, \ldots, m
\end{gathered}
$$


Where $w_{k}$ is the weight associated to the criterion $k$ for the alternative $i$. Weights estimation can be sometimes very difficult and highly subjective. In line with DEA methodology, the linear program in Equation 2 is computed separately for each alternative. The weights in the objective function $\left(w_{k} \geq 0, k=1, \ldots, m\right)$ are chosen optimally with the purpose of maximizing the score of the evaluated alternative. The optimization ensures that each alternative is evaluated on the bases of its own best possible weights, in this way it is put in its most favourable light, and any other weighting scheme would generate a lower global score. As in the standard PROMETHEE, the constraint (Equation 2) ensures that the sum of the weights is equal to 1 for all the evaluated alternatives.

In addition to the global score $\phi\left(a_{i}\right)$, the optimization in Equation 2 provides information about the performance in each criterion considered. For each alternative $(i)$, a high $w_{k}$ signals a good performance in the criterion $(k)$. Moreover, supplementary information can be obtained by a "pessimistic" optimization on the same unicriterion net flows $\phi_{k}\left(a_{i}\right)$ as follows:

$$
\begin{gathered}
\phi\left(a_{i}\right)=\min _{u_{k}} \sum_{k=1}^{m} \phi_{k}\left(a_{i}\right) u_{k} \\
\sum_{\substack{k=1 \\
u_{k}}}^{m} u_{k}=1 \\
0, k=1, \ldots, m
\end{gathered}
$$

The linear program in Equation 3 is computed separately for each alternative, and the weights in the objective function $\left(u_{k} \geq 0, k=1, \ldots, m\right)$ are chosen optimally with the purpose of minimizing the score of the evaluated alternative. By the optimization (Equation 3) each alternative is evaluated on the bases of its own less favourable possible weights, therefore for each alternative $(i)$ a high $u_{k}$ obtained by Equation 3 signals a bad performance in the criterion $(k)$. It is worth noting that with the optimizations in Equation 2 and 3 weights assume a value only for the pollutant in which the country performs better. More in details, looking at the weights in Figure 3 it can be noted that the weights assume the value of one (the maximum) for one specific pollutant for observation (country/year), and assume the value of zero for all the others pollutants. On the bases of this evidence, double counting can be excluded using PROMETHEE-OW.

In the next section, the models presented in Equation 2 and 3 are applied to European countries, using pollutants as criteria. Ranking is performed simultaneously for all years (2008-2015) and countries in order to obtain valid comparisons among both different periods and different countries. Moreover, in this study we employ a level preference function with $p=0$ so that any difference within criteria is relevant for ranking, but the methodological innovation presented in Equation 2 and 3 can be applied to all shapes of preference function are proposed in PROMETHEE (Brans and Vincke, 1985). 


\section{The data}

The dataset exploited in this study is provided by the AEA accounts (Air Emissions Account) collected yearly by Eurostat (2018) for the seven-year period 2008-2015. AEA accounts report emissions assigned to the country according to the residence principle (i.e. the residence of the operator causing the emission). The list of pollutants included in the analysis embraces 10 air pollutants that are particularly harmful for human health and environmental balance when highly concentrated in the atmosphere (see Table 1).

\section{(Table 1 about here)}

The working sample provided by Eurostat consists 30 European countries, namely all EU28 members except Norway and Switzerland. They have been chosen as these countries are economically and politically wellconnected with each other by means of their similar institutional framework. By preventing very distinctive pathdependent or developmental stage caused patterns, these commonalities put countries on a path to converge towards "green-related" issues, thus improving the quality of the comparison when environmental performances are investigated at the country level.

On the other hand, the time window 2008-2015 is mainly caused by data availability as the use of other sources for enlarging the final sample would have produced not comparable data. This period also coincides with the recent recession experienced by EU countries. So that, as production processes represent the main source of polluting activities, such a time restriction may allow to better understand environmental performances at the country-level by controlling for decreases industrial production due to the 2008 crisis. To this purpose, emissions expressed in absolute values are divided by the ratio between the gross value added of manufacturing and the gross value-added sourced from all economic activities (Table 2).

\section{(Table 2 about here)}

Figure 1 shows the percentage of manufacturing value added over total gross value added between 2008 and 2015 for the countries of our sample.

\section{(Figure 1 about here)}

\section{Results}

In this study, we apply PROMETHEE-OW in order to estimate a composite index of environmental performances in 30 European countries by considering the country-level emissions of 10 polluting substances. We focus on environmental performance by using the ratios between the $\mathrm{kg}$ of each of the 10 pollutants and the share of gross value added of manufacturing on gross value-added sourced from all activities, as criteria. For all the 30 countries of the sample, Figure 2 shown the trend of the global scores $\phi\left(a_{i}\right)$ calculated with Equation 2 (black line) and, contextually, the level of GHG emissions in $\mathrm{CO} 2 \mathrm{e}$ divided by the ratio between the gross value added of manufacturing and the gross value-added sourced from all economic activities (red line). Such a comparison allows to fully appreciate in which cases a multi-criteria approach may be more informative than a single indicator 
approach $\left(\mathrm{CO}_{2} \mathrm{e}\right)$ which, contrary to the former, does not account for all pollutants and makes use of common weights. In fact, we observe divergence paths in many cases. For example, Bulgaria, Croatia, Cyprus, Greece, Lithuania and Luxembourg are recording global scores less than 0 but show good environmental performances when expressed in $\mathrm{CO}_{2} \mathrm{e}$ units. This means that, for the above cases, using a single metric approach may pose the risk to overestimate the environmental performance of these countries. Such a divergence is even huge for Italy and Poland, whose global score trend is found below -0.5. On the contrary, the high global score shown by France is not paralleled by a low level of $\mathrm{CO}_{2} \mathrm{e}$ emissions, thus suggesting that when including other pollutants and using differentiated weights France performs better. Similarly, UK appears to perform better with the PROMETHEEOW than $\mathrm{CO}_{2}$ e standard, whose trend turns out to be particularly bad.

\section{(Figure 2 about here)}

More in general, to further acknowledge how marked are the differences in results for all the 30 European countries when passing from a single to a multi-criteria approach, Figure 3 provides a static comparison between two different maps: (a) the one grouping countries according the standard deviation from the mean of the synthetic CO2e index mean value measured over the period 2008-2015; (b) the second grouping countries according the standard deviation from the mean of global score mean value referred to the same time window.

\section{(Figure 3 about here)}

Focusing on Figure 3b, which is obtained by performing the new PROMETHEE-OW approach, we classify environmental performances at the country level by grouping together those countries with similar global score. In particular, by looking at the standard deviation values $(\sigma=.559)$ from the mean $(\mu=.207)$, we identify four groups and one outlier. In the case of normal distribution, $68 \%$ of values should be within mean $-+1 * \sigma$, while $95 \%$ of values should be within mean $-+2 * \sigma$. Therefore, four groups are there defined as follows:

(i) good performers as Austria, Estonia, Finland, Ireland and Malta, with global score greater than the mean plus 1 standard deviation and below the mean plus 2 standard deviations;

(ii) medium-good performers as Belgium, Czech Republic, Denmark, France, Hungary, Lithuania, Netherlands, Portugal, Slovakia, Slovenia, Spain, Sweden, Switzerland and United Kingdom with global score greater than the mean and below the mean plus 1 standard deviation;

(iii) medium-bad performers as Bulgaria, Croatia, Cyprus, Greece, Luxemburg and Netherlands with global score below the mean and above the mean minus 1 standard deviation;

(iv) bad performers as Germany, Latvia, Poland, and Romania with global score below the mean minus 1 standard deviation and above the mean minus 2 standard deviation.

The outlier country turns out to be Italy (the lowest performer), with a global score below the mean minus 2 standard deviations.

By focusing on global score trends occurring over the period 2008-2015, we observe an almost stable classification without remarkable changes in those scores. The dynamic of the scores shows a general stability or a moderate increase is most of the analysed cases. However, it could be stressed the virtuous behaviour of countries such as 
Belgium, Bulgaria, Czech Republic, France and Ireland, which show the highest increase in global score over the period under investigation. On the contrary, Italy, Lithuania, Spain and Sweden are those countries where the most significant decreases in global scores are recorded during the period 2008-2015 (Figure 4).

\section{(Figure 4 about here)}

Finally, Figure 5 shows the minimum and maximum weights associated, in each year and each country, among pollutants. Those weights are presented from two perspectives: optimistic by means of the optimization in program (Equation 2); and pessimistic by means of the optimization in program (Equation 3). In the first one, the pollutants with the higher weights could be interpreted corresponding to countries that have a relative good performance and the opposite in the other perspective. Therefore, it is possible to sensitize these weights, evidencing those pollutants in which each country has relative good and bad performance. A bulk of countries, including Austria, Czech Republic, Denmark, Portugal, Romania, Slovakia, Slovenia, Sweden, and Switzerland show more stable patterns both for good and bad perspectives, while pollutants associated with the remaining countries change over time, especially in the cases of Croatia, France, Greece, Ireland, Italy, Malta, and Netherlands.

\section{(Figure 5 about here)}

\section{Discussion}

The above classification reflects the differences in terms of economy structure at country-level. In general, most of the countries belonging to the group of good and medium-good performers are mainly characterized by servicesbased and knowledge-intensive economies. As a consequence, given the secondary role played by the manufacturing industry in the above-mentioned cases, good performers' emissions turn to be lower when compared with manufacturing-focused economies. This may reflect the case of Malta, whose economic structure is mainly focused on the service sector. In addition, good and medium-good environmental performance could be linked to other reasons. Firstly, as in the case of Ireland (Figure 2), high valued added in manufacturing activities could increase the global score by raising the value of the denominator in the measurement, thus leading to better performance. In fact, during the last decade, the Irish government has increased public funding for academic research in order to attract higher value foreign direct investments and increase the dynamism of its indigenous enterprise base in these activities (Ramirez et al., 2016). Secondly, good environmental scores could be associated with successfully environmental policies specifically designed for the industrial sector. For example, the greening process involving industrial policies during the last decade in Estonia has improved innovation in the field of environmental technology and higher value-added activities in the use of renewable natural resources, by leading the country to overperform in environmental issues (Pilvik, 2014). Thirdly, as in the cases of France and Portugal, another aspect linked to good environmental performance could be recognized in the low-carbon footprint of the energy supply. In France, nuclear energy plays a key role in the country energy mix (IEA, 2017a), while Portugal's positioning is mainly due to its mass use of renewable sources (hydroelectric dams and wind power) in the energy 
supply composition, that account for the most of mainland electricity consumption (in March 2018 it raised up to 103.6\%) (APREN, 2018). Finland and Sweden registered a remarkable decrease in their manufacturing industries' value-added during the period 2008-2015, thus focusing their economies on knowledge-based and service sectors. Moreover, both countries made strong efforts to promote renewable energy systems. For example, with the largest percentage of forest cover in the European area (more than 70\%) (FAO, 2018) — which is a major source of carbon sequestration-Finland registered the higher rates on GHG reduction in 2011 and 2012 (WB, 2017), fuelled by the ambitious goal to reach $38 \%$ of their consumption from renewable resources from 2020 (IEA, 2013a). Sweden is instead considered one of the countries in the IEA framework that made the strongest efforts since 2008 to achieve low-carbon intensity and high share of renewable energy in the total energy supply. It has also the ambitious target of achieving a fossil fuel-independent vehicle fleet by 2030 and zero net GHG emissions by 2050 (IEA, 2013c).

Regarding the bad performers of Germany, Latvia, Poland, Romania and the outlier Italy, their low scores are mainly associated with their manufacturing-focused economies characterized by low value-added and/or energy intensive activities. In fact, almost $30 \%$ of the total employment in these countries is located in the industrial sector (WB, 2018). In addition, when compared with better performers, those countries are often characterized by less successful environmental policy programs as in the case of Latvia, where the Green Investment Scheme (GIS) launched to reduce energy consumption in the industrial sector appears to work not effectively (Ozolina and Rosā, 2012). Moreover, the degree of sustainability in the energy supply is another relevant element for distinguishing between good and bad performers. For example, among the latter, Poland is the one which is still dominated by high-carbon footprint sources with an energy mix composed of $80 \%$ (in 2015) coal power production (Janeiro and Resch, 2017). In contrast, in the case of Romania, the decrease of the manufacturing sector value probably represented the main cause of its bad behaviour. In addition, given that these countries have the lowest amount of employment in the services sector, the primary role of industrial and agricultural sectors leads to lower environmental efficiency (WB, 2018). The case of Germany and Italy is for sure peculiar since they are considered as two countries that have overcome their so-called Environmental Kuznets Curve (EKC) and are now in their decreasing phase of $\mathrm{CO}_{2}$ emissions (e.g. Mazzanti and Musolesi, 2013; Shahbaz et al., 2017). However, in the EKC literature, commonly only one pollutant is considered $\left(\mathrm{CO}_{2}\right)$ and is averaged by total population. Moreover, Italy and Germany showed also good sustainable performance according to Antanasijevic et al. (2017) during the period 2004-2014. Therefore, the choice to implement a multi-criteria approach that considers different weights, pollutants and which has a particular focus on the sustainability of the industrial sector leads once again to different results. Nevertheless, both Italy and Germany have implemented ambitious programmes for their future, such as the National Energy Strategy (2013) and the Energy Concept (2010), respectively, with the aim of boosting their energy sectors toward higher renewable structures (IEA, 2013b, 2017b). Moreover, from an environmentaloriented policy perspective, particular attention must be pointed towards the pollutants determining good and bad performance of the countries. In particular, $\mathrm{NH}_{3}, \mathrm{PM}_{2.5}$, and $\mathrm{SO}_{\mathrm{X}}$, turn to be the most common pollutants associated 
with pessimistic perspectives. However, given that the above pollutants directly and indirectly enter into several economic activities (Table 1), there is reason to believe that defining a specific line of policy intervention requires much effort. In this regard, when environmental goals are settled by governments and institutions, the issue of complexity that arises from the present empirical analysis needs to be taken into account. Rather than rely only on the indicator of GHG pollutants, that is the common $\mathrm{CO}_{2} \mathrm{e}$ measure, our score is able to provide a larger perspective over time of the air-pollution path of European countries. Furthermore, by knowing good and bad performances, each country can identify flaws and strengths of their manufacturing sector in terms of emissions. For example, in the last group of countries, Italy and Germany have to put efforts in decreasing mainly $\mathrm{CH}_{4}$ and $\mathrm{SO}_{\mathrm{x}}$ emissions, Poland on NMVOC and $\mathrm{N}_{2} \mathrm{O}$ while Romania, with a more mixed behaviour, on $\mathrm{CO}$, NMVOC, and $\mathrm{SO}_{\mathrm{x}}$.

\section{Conclusions}

We propose to overcome the common $\mathrm{CO}_{2}$ measure and investigate the European environmental context from a multi-dimensional perspective. We implemented PROMETHEE-OW to evaluate 10 groups of pollutants for each country over the period 2008-2015. Compared with other techniques implemented for composite indicators, the main advantages of PROMETHEE-OW are in the weighting and aggregation process. Regarding the weights, PROMETHEE-OW uses different vector weights for different units that allow us to take into account the different technologies in the spirit of Data Envelopment Analysis. Regarding the aggregation, PROMETHEEOW is non-compensatory, as it is based on PROMETHEE. The main findings stem from the comparison between PROMETHEE-OW and $\mathrm{CO}_{2} \mathrm{e}$ results (Figure 2), whose analysis encloses relevant policy implications. Here we argue that, in those countries where the two trends diverge, the use of a single-metric approach $\left(\mathrm{CO}_{2} \mathrm{e}\right)$ may pose the risk of affecting environmental performances evaluation as no attention is paid to two pillar issues: (i) the complete array of air pollutants and (ii) their common weighing. Such a risk appears particularly relevant for a bulk of countries (Bulgaria, Croatia, Cyprus, Greece, Lithuania, Luxembourg, Italy, and Poland) for which PROMETHEE-OW shows worse performances than those emerging when the $\mathrm{CO}_{2} \mathrm{e}$ is used. On the other hand, France and UK are likely to behave better when their environmental performances are evaluated with PROMETHEE-OW. So that, we claim that the two approaches are inherently dissimilar also in terms of the outcomes provided to policy makers as countries that appear to perform well within the $\mathrm{CO}_{2}$ approach do the contrary within the PROMETHEE-OW, and vice-versa. In addition to this, we sustain that PROMETHEE-OW might be also more informative by means of the weights produced in the optimizations. From our results, it is possible to classify European countries into groups according to their relative performances. Good, medium-good, medium-bad, and bad performers. Countries with good performance are characterized by economic structures, which are more services- and knowledge-oriented, environmental policies which spur the industrial sector, and/or demonstrate improvement in the energy mix. Conversely, countries with bad performances have important industrial sectors but with low value-added and/or a low green energy mix. Moreover, we identified pollutants in 
which countries have relative good and bad performances, providing a tool to identify which areas require more attention from policy makers.

In conclusion, the main implication of our analysis is that considerable efforts should be made to identify the sources of inefficiencies emerging when countries' environmental performances are evaluated by considering a plethora of polluting substances which differently affect environment and human health. Expressing countries' trends in $\mathrm{CO}_{2} \mathrm{e}$ terms does not help to do so. In fact, since they not include all the pollutants, synthetic $\mathrm{CO}_{2} \mathrm{e}$ indicators are not useful from the point of view of environmental policy design. Nonetheless, countries are still evaluated on the basis of the amount of the emissions expressed in $\mathrm{CO}_{2}$, with the worrisome property that these values do not take into account the whole spectrum of polluting substances as well as their inner differences. To have a real impact on the design of environmental policies of the EU Member States, here we argue that a multicriteria approach may help to prevent from misleading researchers, policy makers, politicians, as well as the general public. Policy makers in the field of environmental policy should be able to identify the policy problems in their environmental performance and relate them to their causes to be able to select policy instruments to mitigate the problems. So that, our approach can be useful for a better policy design. Further development could be oriented to emissions from different sources (e.g. industrial, residential, transportation) and a more disaggregate analysis focused on regions rather than European countries.

\section{References}

Antanasijević, D., Pocajt, V., Ristić, M., \& Perić-Grujić, A. (2017). A differential multi-criteria analysis for the assessment of sustainability performance of European countries: Beyond country ranking. Journal of Cleaner Production, 165, 213-220. 
APREN (2018). Março $100 \%$ renovável - primeiro mês com consumo de eletricidade assegurado por fontes renováveis é record de enorme relevância, Associação Portuguesa de Energias Renováveis. Retrieved from: $\quad$ http://www.apren.pt/pt/marco-100-renovavel--primeiro-mes-com-consumo-de-eletricidadeassegurado-por-fontes-renovaveis-e-record-de-enorme-relevancia [Accessed April 1, 2018].

ATSDR (1998). Public health statement: Sulfur Dioxide. Retrieved from: https://www.atsdr.cdc.gov/ToxProfiles/tp116-c1-b.pdf [Accessed November 1, 2018]

ATSDR (2014). Medical Management Guidelines for Ammonia. Retrieved from: https://www.atsdr.cdc.gov/mmg/mmg.asp?id=7\&tid=2 [Accessed November 1, 2018]

Ayoko, G., Morawska, L., Kokot, S., and Gilbert, D. (2004). Application of multicriteria decision making methods to air quality in the microenvironments of residential houses in Brisbane, Australia. Environmental Science \& Technology, 38(9): 2609-2616.

Borghesi, S. (2011). The European emission trading scheme and renewable energy policies: Credible targets for incredible results? International Journal of Sustainable Economy, 3(3):312-327.

Brans, J. and Vincke, P. (1985). Note-A Preference Ranking Organisation Method: (The PROMETHEE Method for Multiple Criteria Decision-Making). Management Science, 31(6):647-656.

Brans, J. P., \& De Smet, Y. (2016). PROMETHEE methods. In Multiple Criteria Decision Analysis (pp. 187-219). Springer, New York, NY.

Brans, J., Vincke, P. and Mareschal, B. (1986). How to select and how to rank projects: The PROMETHEE method, European Journal of Operational Research, 24(2): 228-238.

Brunekreef, B. and Holgate, S. T. (2002). Air pollution and health. The Lancet, 360(9341):1233-1242.

CDCP (2018). Emergency Preparedness and Response: Facts About Benzene. Retrieved from: https://emergency.cdc.gov/agent/benzene/basics/facts.asp [Accessed November 1, 2018]

Charnes, A., Cooper, W. W., and Rhodes, E. (1978). Measuring the efficiency of decision making units. European Journal of Operational Research, 2(6):429-444.

Cherchye, L., Moesen, W., Rogge, N., and Van Puyenbroeck, T. (2007). An introduction to 'benefit of the doubt' composite indicators. Social Indicators Research, 82(1), 111-145.

Crnković, D. M., Antanasijević, D. Z., Pocajt, V. V., Perić-Grujić, A. A., Antonović, D., \& Ristić, M. Đ. (2016). Unsupervised classification and multi-criteria decision analysis as chemometric tools for the assessment of sediment quality: A case study of the Danube and Sava River. Catena, 144, 11-22.

Coban, A., Ertis, I. F., \& Cavdaroglu, N. A. (2018). Municipal solid waste management via multi-criteria decision making methods: A case study in Istanbul, Turkey. Journal of Cleaner Production, 180, 159-167.

Costanza, R., Daly, L., Fioramonti, L., Giovannini, E., Kubiszewski, I., Mortensen, L. F., ... and Wilkinson, R. (2016). Modelling and measuring sustainable wellbeing in connection with the UN Sustainable Development Goals. Ecological Economics, 130:350-355. 
Decancq, K. and Lugo, M. A. (2013). Weights in multidimensional indices of wellbeing: An Overview. Econometric Reviews, 32(1):7-34.

Deljanin, I., Antanasijević, D., Bjelajac, A., Urošević, M. A., Nikolić, M., Perić-Grujić, A., \& Ristić, M. (2016). Chemometrics in biomonitoring: Distribution and correlation of trace elements in tree leaves. Science of the Total Environment, 545, 361-371.

EPA (2018a). Global Greenhouse Gas Emissions Data. Accessible at: https: . //www.epa.gov/ghgemissions/overview-greenhouse-gases\#methane [Accessed April 2018].

EPA (2018b) Understanding global warming potentials. United States Environmental Protection Agency. Retrieved from: https://www.epa.gov/ghgemissions/understanding-global-warming-potentials [Accessed April 1, 2018].

EUROSTAT (2018). Air pollutants by source sector. Retrieved from: http://ec.europa.eu/eurostat/web/environment/ air-emissions-inventories/database [Accessed February 2, 2018].

FAO (2018). FAOSTAT. Food and Agricultural Organization of the United Nations. Retrieved from: http://www.fao.org/faostat/en/\#home [Accessed April 1, 2018].

Floridi, M., Pagni, S., Falorni, S., \& Luzzati, T. (2011). An exercise in composite indicators construction: Assessing the sustainability of Italian regions. Ecological economics, 70(8), 1440-1447.

Greco, S., Ishizaka, A., Tasiou, M., and Torrisi, G. (2018). On the methodological framework of composite indices: A review of the issues of weighting, aggregation, and robustness. Social Indicators Research: 1-34.

Henry, C. R., Satran, D., Lindgren, B., Adkinson, C., Nicholson, C. I., \& Henry, T. D. (2006). Myocardial injury and long-term mortality following moderate to severe carbon monoxide poisoning. Jama, 295(4), 398402.

IEA (2013a). Energy Policies of IEA Countries: Finland 2013 Review, International Energy Agency, OECD/IEA. IEA (2013b). Energy Policies of IEA Countries: Germany 2013 Review, International Energy Agency, OECD/IEA.

IEA (2013c). Energy Policies of IEA Countries: Sweden 2013 Review, International Energy Agency, OECD/IEA. IEA (2016). World Energy Outlook 2016, International Energy Agency, OECD/IEA.

IEA (2017a). Energy Policies of IEA Countries: France 2016 Review, International Energy Agency, OECD/IEA. IEA (2017b). Energy Policies of IEA Countries: Italy 2016 Review, International Energy Agency, OECD/IEA. IPCC (2007). Climate Change 2007: The Physical Science Basis. Contribution of Working Group I to the Fourth Assessment Report of the Intergovernmental Panel on Climate Change, Cambridge University Press, Cambridge, United Kingdom and New York, NY, USA, IPCC (2015). Climate change 2014: Mitigation of climate change. Cambridge University Press. Intergovernmental Panel on Climate Change. 
Irga, P. J., Burchett, M. D., and Torpy, F. R. (2015). Does urban forestry have a quantitative effect on ambient air quality in an urban environment? Atmospheric Environment, 120:173-181.

Ishizaka A. and Pereira V. (2016). A fair and transparent employee performance management system based on multi-criteria decision analysis and visual techniques. International Journal of Manpower, 37(4):628-659.

Ishizaka, A. and Nemery, P. (2013), Multi-criteria decision analysis: Methods and software. John Wiley \& Sons. Janeiro, L. and Resch G. (2017). 2020 Renewable Energy Target Realisation Forecast for Poland Final Report, Project number: EPODE17004, Ecofys.

Kampa, M., and Castanas, E. (2008). Human health effects of air pollution. Environmental Pollution, 151(2): 362367.

Laurent, A., \& Hauschild, M. Z. (2014). Impacts of NMVOC emissions on human health in European countries for 2000-2010: Use of sector-specific substance profiles. Atmospheric environment, 85, 247-255.

Mazzanti, M. and Musolesi, A. (2013). The heterogeneity of carbon Kuznets curves for advanced countries: Comparing homogeneous, heterogeneous and shrinkage/Bayesian estimators. Applied Economics, 45(27), 3827-3842.

Munda, G. (2012). Choosing aggregation rules for composite indicators. Social Indicators Research, 109(3):337354.

Munda, G. and Nardo, M. (2009). Noncompensatory/nonlinear composite indicators for ranking countries: A defensible setting. Applied Economics, 41(12):1513-1523.

Nardo, M., Saisana, M., Saltelli, A., Tarantola, S., Hoffman, A., Giovannini, E. (2008). Handbook on Constructing Composite Indicators. Paris: OECD-JRC.

Naturvårdsverket. (2018). Greenhouse Gases. Accessible at: https: //utslappisiffror.naturvardsverket.se/en/Substances/Greenhouse-gases/ [Accessed March 2018].

Nemery, B., Hoet, P. H., and Nemmar, A. (2001). The Meuse Valley fog of 1930: An air pollution disaster. The Lancet, 357(9257):704-708.

Nikolić, D., Milošević, N., Mihajlović, I., Živković, Ž., Tasić, V., Kovačević, R., and Petrović, N. (2010). Multicriteria analysis of air pollution with so 2 and pm 10 in urban area around the copper smelter in Bor, Serbia. Water, Air, and Soil Pollution, 206(1-4):369-383.

OECD (2016). How's Life? 2016 - Measuring Well-being. Paris.

Ozoliņa, L. and Rosā, M. (2012). A review of energy efficiency policy and measures for industries in Latvia. Management of Environmental Quality: An International Journal, 23(5):517-526.

Paruolo, P., Saisana, M., and Saltelli, A. (2013). Ratings and rankings: voodoo or science? Journal of the Royal Statistical Society: Series A (Statistics in Society), 176(3):609-634.

Patrizii, V. and Resce, G. (2015). Public Sector Contribution to Competitiveness. Italian Economic Journal, 1(3):401-443.

Patrizii, V., Pettini, A., Resce, G. (2017). The Cost of Well-Being. Social Indicators Research, 133(3):985-1010. 
Pilvik, R. (2014). Assessment of climate change policies in the context of the European Semester. Country Report: Estonia. Ecologic Institute - Eclareon.

Ramirez, P., Love, J. H., and Vahter, P. (2016). Industry-academic links: A new phase in Ireland's FDI-led industrialisation strategy. European Urban and Regional Studies, 23(2):167-181.

Ravishankara, A. R.; Daniel, J. S.; Portmann, R. W. (2009). Nitrous Oxide (N2O): The Dominant Ozone-Depleting Substance Emitted in the 21st Century. Science, 326(5949): 123-5.

Shafik, N. and Bandyopadhyay, S. (1992). Economic growth and environmental quality: Time-series and crosscountry evidence, volume 904. World Bank Publications.

Shahbaz, M., Shafiullah, M., Papavassiliou, V. G., and Hammoudeh, S. (2017). The CO2-growth nexus revisited: A nonparametric analysis for the G7 economies over nearly two centuries. Energy Economics, 65:183193.

Thrane, V. R., Thrane, A. S., Wang, F., Cotrina, M. L., Smith, N. A., Chen, M., ... \& Nedergaard, M. (2013). Ammonia triggers neuronal disinhibition and seizures by impairing astrocyte potassium buffering. Nature medicine, 19(12), 1643-1648.

Tofallis, C. (2008). Selecting the best statistical distribution using multiple criteria. Computers \& Industrial Engineering, 54(3): 690-694.

UNFCCC (2018). The Paris agreement. Retrieved from: http://unfccc.int/ paris_agreement/items/9485.php [Accessed February 2018].

Wendling, Z. A., Emerson, J. W., Esty, D. C., Levy, M. A., de Sherbinin, A., et al. (2018). 2018 Environmental Performance Index. New Haven, CT: Yale Center for Environmental Law \& Policy. Retrieved from: https://epi.yale.edu/ [Accessed November 1, 2018].

WB (2017). World development indicators. Retrieved from: http: //data.worldbank.org/data-catalog/worlddevelopment-indicators [Accessed December 2017].

WHO (2013). Health effects of particulate matter. Policy implications for countries in eastern Europe, Caucasus and central Asia. World Health Organization. Retrieved from: http://www.euro.who.int/_data/assets/pdf_file/0006/189051/Health-effects-of-particulate-matter-finalEng.pdf [Accessed November 1, 2018]

WHO (2018). Air Pollution. World Health Organization. Retrieved from: http: //www.who.int/topics/air_pollution/en/ [Accessed January 18, 2018]. 
Table 1. Man-made emissions' sources

\begin{tabular}{llll}
\hline \multicolumn{1}{c}{ Pollutant } & Label & Human-related sources & Main damages for human-being \\
\hline Methane & $\mathrm{CH} 4$ & $\begin{array}{l}\text { Livestock farming, production } \\
\text { of fossil fuels, wet rice } \\
\text { cultivation, biomass burning, } \\
\text { landfill and domestic sewage, } \\
\text { chemical industry, power } \\
\text { stations, residential buildings. }\end{array}$ & $\begin{array}{l}\text { Relatively small health damages; } \\
\text { however, it represents one of the } \\
\text { major greenhouse gases (indirect } \\
\text { effects). }\end{array}$ \\
& Transport processes. & $\begin{array}{l}\text { The exposure produces several } \\
\text { health problems, reduction of life } \\
\text { expectancy and death. }\end{array}$
\end{tabular}


Carbonic dioxide

$\mathrm{CO} 2$

Nitrous Oxides

$\mathrm{N} 2 \mathrm{O}$

$\mathrm{NH} 3$

Ammonia

Non-methane volatile organic compounds

Nitrous oxide

Particulate matter (10 micrometres

diameter)

Particulate matter (2.5 PM2_5 micrometres diameter)

Sulphur dioxide
NMVOC

Transport and industrial processes.
Agricultural and industrial processes, combustion of fossil fuels, solid waste.

Use of fertilizers and waste disposal sites or industrial processes. and other processes where fuels containing carbon are burnt.

gases, environmental implication (indirect effects).

Minor direct problems such as nausea or vomiting; however, despite its low harmfulness, it represents one of the main scavengers of the stratospheric ozone (indirect effects).

Neuronal disinhibition, irritation and corrosion of skin, eyes, and the respiratory system.

Respiratory and cardiovascular system damages, acute chronic diseases, carcinogenic and mutagenic effects. Damages on crops (indirect effect).

Transport sector and energy sector.

Power plants, industrial facilities, fires, and cars.

Construction sites, unpaved roads, fires, and cars.
Damages on soil, water, and forests (indirect effect).

Damages for the respiratory system, asthma, cardiovascular problems, hearth attacks, lung cancer.

Damages for the respiratory system, asthma, cardiovascular problems, hearth attacks, lung cancer, cardiopulmonary mortality.

Damages for lung functions, irritation and obstruction of the respiratory system. and other large industrial plants, motor vehicles, and domestic boilers. 
Sources: ATSDR (1998, 2014), Henry et al. (2006), Ravishankara et al. (2009), Thrane et al. (2013), WHO (2013), Laurent and Hauschild (2014), Naturvårdsverket (2016), CDCP (2018), EEA (2018), EPA (2018a,b), EUROSTAT, (2018).

Table 2. Descriptive statistics (kilograms per capita)

\begin{tabular}{cccc} 
Variable & Mean & Min & Max \\
\hline CH4 & 53.410 & 0.078 & 1003.820 \\
CO & 20.510 & 0.003 & 327.330 \\
NO2 & 8980.960 & 41.164 & 170657.400 \\
N2O & 1.996 & 0.002 & 33.136 \\
NH3 & 10.924 & 0.020 & 211.932 \\
NMVOC & 14.044 & 0.028 & 283.397 \\
NOX & 26.569 & 0.039 & 507.182 \\
PM10 & 3.638 & 0.005 & 55.372 \\
PM2_5 & 2.216 & 0.003 & 44.841 \\
SOX_SO2 & 15.123 & 0.046 & 250.456 \\
\hline
\end{tabular}

Source: EUROSTAT (2018).

Figure 1. Percentage of gross value-added of manufacturing on the total gross value-added 


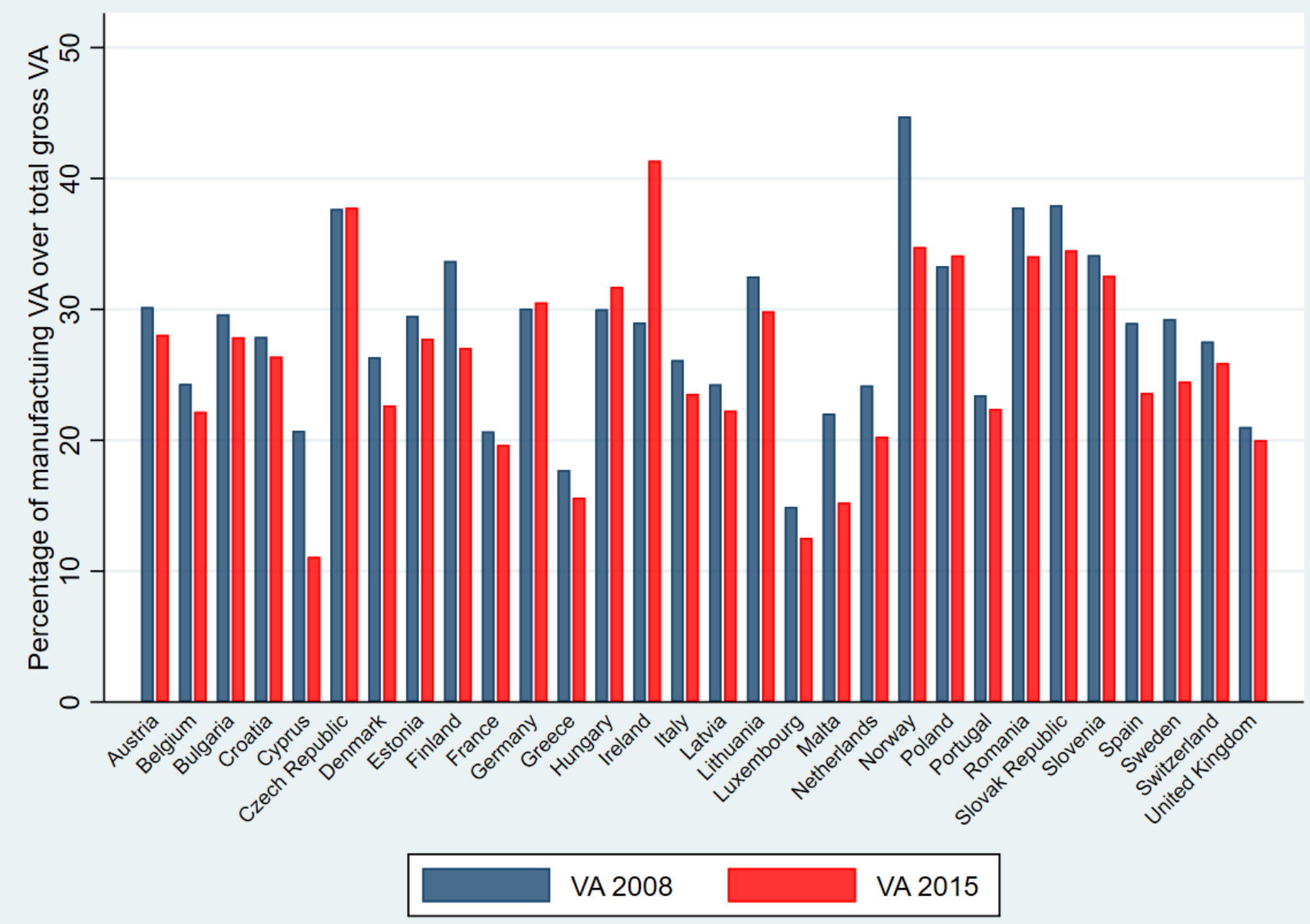

Source: Authors' elaboration based on Eurostat, Annual National Accounts (2018). 


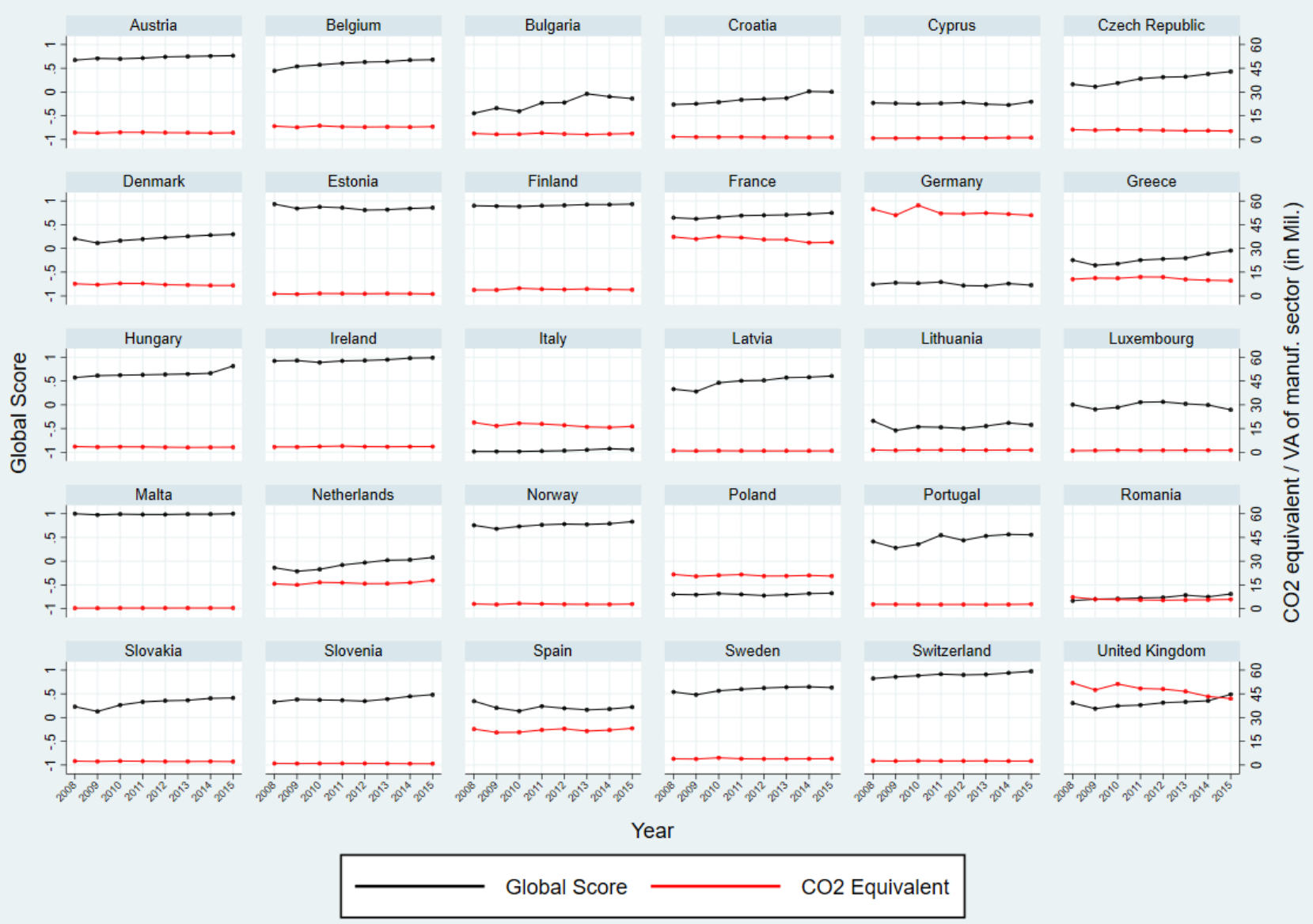

Figure 3. One-single metric approach $\left(\mathrm{CO}_{2} e\right.$, mean value) a) and Multi-criteria approach (PROMETHEE-OW, mean value) b)

Figure 3 a) 


\section{Legend}

$\mathrm{CO}_{2}$ 2008-2015 (mean)

$\square 0-9.92 \mathrm{M},<0$ Std. Dev.

9.92M - 23.49M, $0-1$ Std. Dev.

23.49M - 37.06M, $1-2$ Std. Dev.

$37.06 \mathrm{M}-50.63 \mathrm{M}, 2-3 \mathrm{Std}$. Dev.

$50.63 \mathrm{M}-57.75 \mathrm{M},>=3 \mathrm{Std}$. Dev.

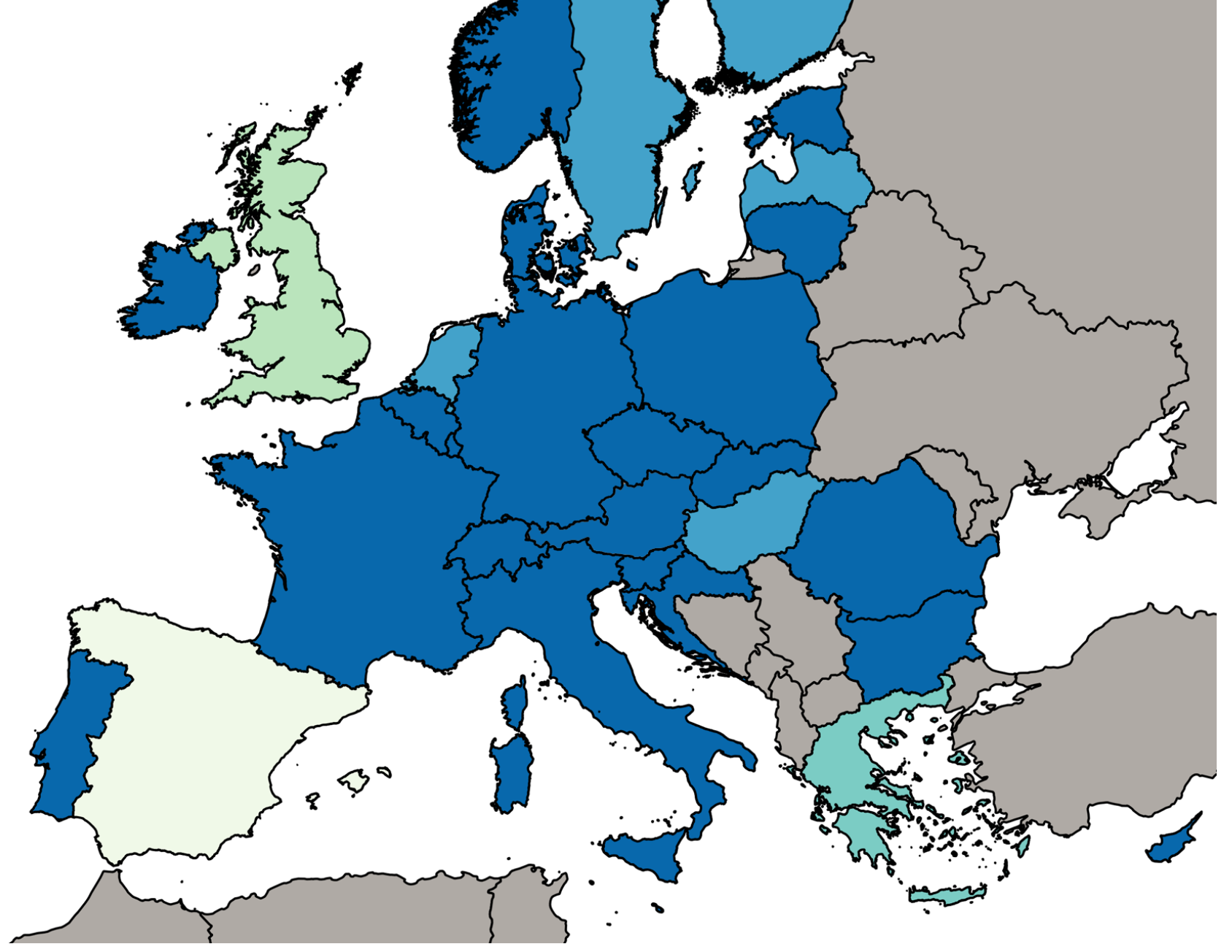

Figure $3 \mathrm{~b}$ ) 


\section{Legend}

Global Score 2008-2015 (mean)

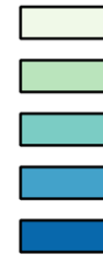

$-0.963--0.912,<-2$ Std. Dev.

$-0.912--0.352,-2--1$ Std. Dev.

$-0.352-0.207,-1-0$ Std. Dev.

$0.207-0.766,0-1$ Std. Dev.

$0.766-0.989,>=1$ Std. Dev.

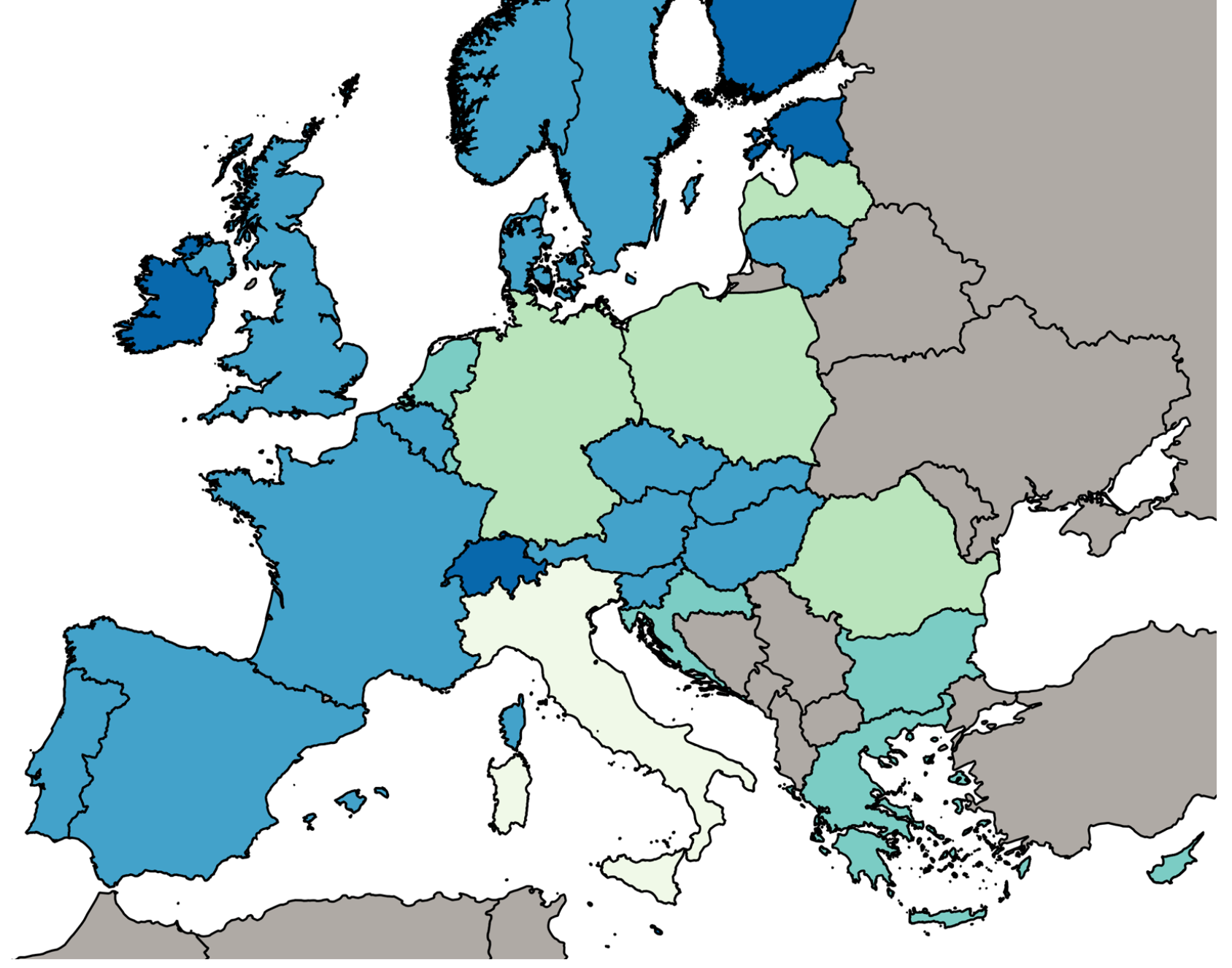

Figure 4. Changes of global scores between 2008 and 2015 


\section{Legend}

$\Delta$ Global Score 2008-2015
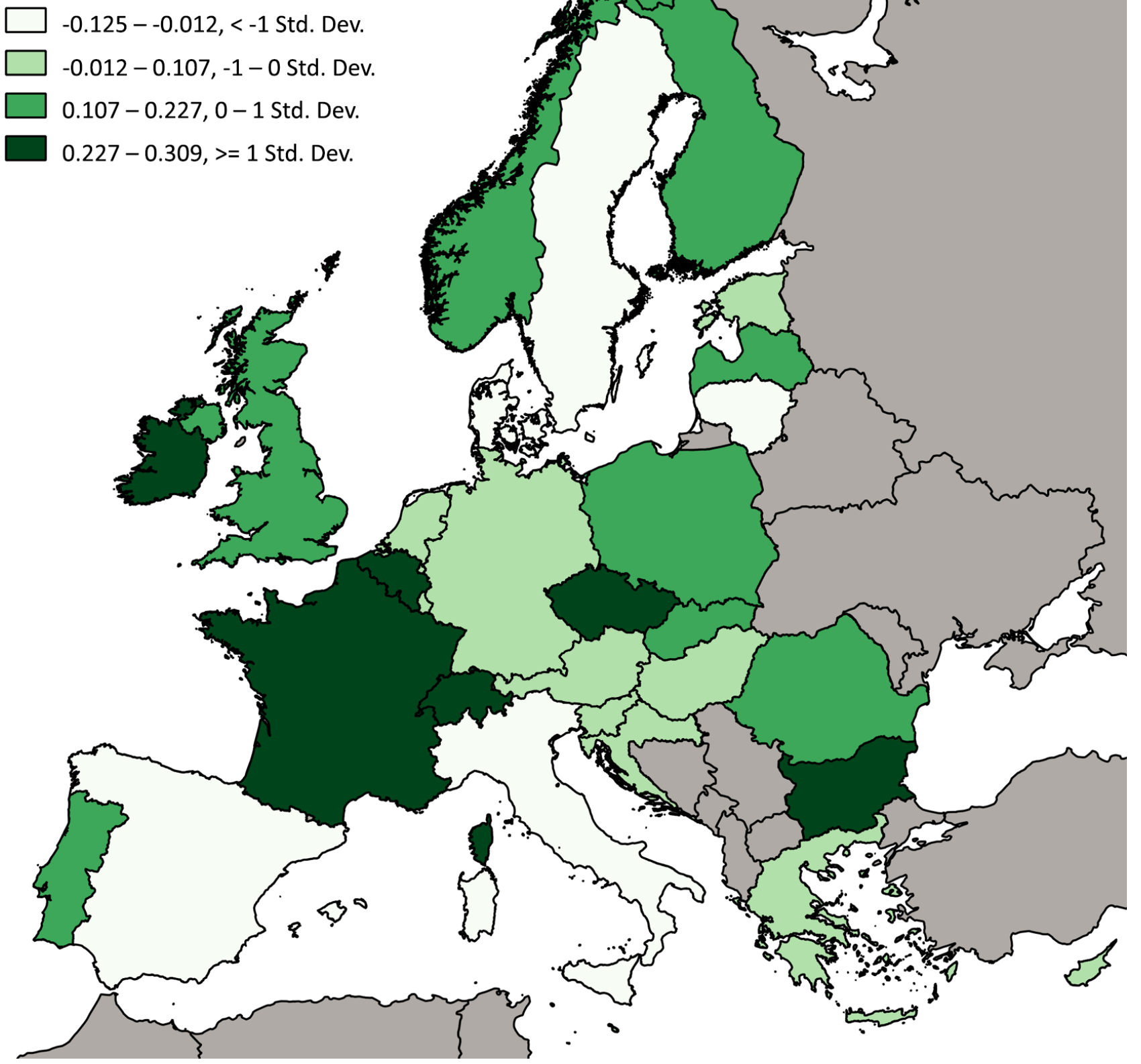

Figure 5. Weights associated with the different substances: optimistic (max) and pessimistic perspectives (min) 


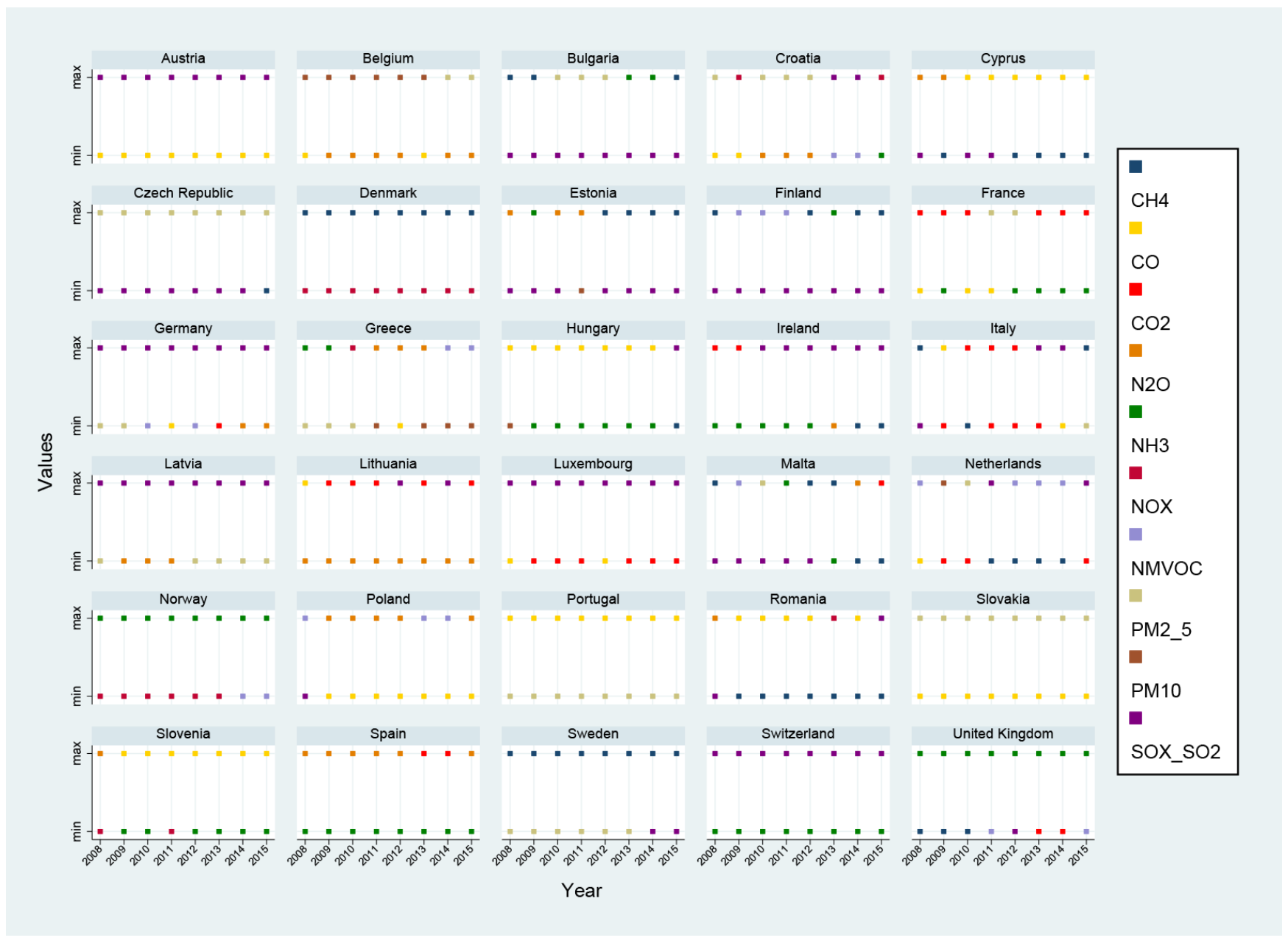

